\section{Line ratio judgments yield subjective lengths proportional to physical lengths: Reanalysis of Engen's data}

\section{RICHARD S. BOGARTZ}

University of Massachusetts, Amherst, Massachusetts 01003

It has been claimed that subjective line length is a nonlinear function of physical line length and that it follows a power function $\mathrm{R}=\mathrm{cS}$, where $\mathrm{R}$ is the subjective length, $S$ is the physical length, and $c$ and $n$ are arbitrary constants. Engen (1971, pp. 71-73) presents data which are intended to support this claim. The purpose of this note is to show that, in fact, Engen's data indicate that subjective line length is proportional to physical line length.

Engen provided data from subjects who judged the ratios of pairs of lines of different length. The lines were $3,4,6,9$, or 12 in. long. His obtained mean ratios are shown in Table 1 . These ratios closely approximate the ratios of the physical values shown in Table 2, suggesting proportionality. Engen, however, reached a different conclusion.

Engen scaled the stimuli using a procedure, described below, which he attributed to Torgerson (1958, pp. 108-112). Using Engen's scale values (see Table 3) and linear regression in the equation $\log \mathrm{R}$ $=\log \mathrm{C}+$ nlog $\mathrm{S}$ yields a Pearson product-moment correlation of $r=.9998$ between Engen's scale values and the logarithms of the physical values. The least squares estimates of $\mathrm{n}$ and $\log \mathrm{c}$ are 1.2455 and -2.2315 , giving the estimated power law $R=$ $.1074 \mathrm{~S}^{1.2455}$. This function gives the predicted scale values of $.4219, .6038,1.0004,1.6577$, and 2.3721 , which are acceptably close to the Engen scale values in Table 3.

Unfortunately, the procedure Engen used actually differed from Torgerson's and introduced a bias. In Torgerson's procedure, the logarithms of the obtained ratios are averaged for each line length and the antilogs of these means are the scale values of the stimuli. Table 3 shows the values obtained by Torgerson's procedure and by Engen's procedure. The difference is that Engen assumed that the row totals should be divided by four, since no entry was made for comparison of lines of equal length. But Torgerson's procedure assumes that lines of equal length will have a ratio of one and that the logarithm of this ratio, zero, will be added in. Thus, Torgerson would divide the same row total by five, not four.

This work was supported by NIMH Grant MH31139. Reprint requests should be sent to Richard S. Bogartz, Department of Psychology, University of Massachusetts, Amherst, Massachusetts 01003 .
Table 1

Mean Judged Ratios of Pairs of Lines

\begin{tabular}{rrrrrrr}
\hline \multicolumn{7}{c}{ Mean Judged Ratios of Pairs of Lines } \\
\hline & & \multicolumn{5}{c}{ Line 2} \\
\hline & 3 & 4 & 6 & 9 & 12 \\
\hline \multirow{4}{*}{ Line 1} & 6 & & .756 & .531 & .326 & .240 \\
& 4 & 1.323 & & .717 & .445 & .328 \\
& 9 & 1.883 & 1.395 & & .669 & .527 \\
& 12 & 4.067 & 2.247 & 1.495 & & .775 \\
\end{tabular}

Table 2

Ratios of the Physical Lengths of Line Pairs

\begin{tabular}{ccccccc}
\hline & & \multicolumn{5}{c}{ Line 2} \\
& 3 & 4 & 6 & 9 & 12 \\
\hline & 3 & & .750 & .500 & .333 & .250 \\
Line 1 & 4 & 1.333 & & .667 & .444 & .333 \\
& 6 & 2.000 & 1.500 & & .667 & .500 \\
& 9 & 3.000 & 2.250 & 1.500 & & .750 \\
& 12 & 4.000 & 3.000 & 2.000 & 1.333 & \\
\hline
\end{tabular}

Reanalysis of Engen's data by linearly regressing the (Torgerson) scale values against the physical values of course again gives a Pearson productmoment correlation coefficient of $r=.9998$. The slope and intercept of the regression line were 6.019 and -.0179 . Since the intercept is essentially zero, the slope was reestimated assuming a zero-intercept regression model, $y=a x+e$. This new slope was 6.003. Multiplying each of the Torgerson scale values by 6.003 gave the values $3.00,4.04,5.91,9.10$, and 11.94 as the new scale values. Using these as the Rs in the power law and using the physical values as the corresponding Ss, the least squares estimates of $c$ and $\mathrm{n}$ are obtained as before using linear regression in the equation $\log R=\log c+n \log S$. The estimates of $n$ and $c$ were .998 and 1.004, respectively. Thus, Engen's data in fact indicate that subjective line length is proportional to physical line length with no suggestion of deviation within the range of values considered. Reanalysis of Comrey's (1950) rather more variable data resulted in a similar finding.

The nature of the bias introduced by Engen's method can be shown as follows. According to the power law, the observed ratio response for stimuli $u$ and $v$ is $R_{u} / R_{v}=\left(S_{u} / S_{v}\right)^{n}$. The logarithm of the ratio is $n\left(\log S_{u}-\log S_{v}\right)$. Assuming a set of I stimuli, the row mean for row $k$ of the table of $\log$ ratios is

$$
I^{-1} \sum_{i} n\left(\log S_{k}-\log S_{i}\right)=n \log S_{k}-I^{-1}\left(\sum_{i} \log S_{i}\right)
$$

The scale value for stimulus $k$, taken as the antilog of this mean, is

$$
S_{k}^{n} \exp \left(I^{-1} \sum_{i} \log S_{i}\right)
$$


Table 3

Logarithms of Mean Judged Ratios and Scale Values Obtained by the Engen and Torgerson Procedures

\begin{tabular}{|c|c|c|c|c|c|c|c|c|c|}
\hline & 3 & 4 & 6 & 9 & 12 & $\begin{array}{l}\text { Engen } \\
\text { Mean }\end{array}$ & $\begin{array}{l}\text { Engen } \\
\text { Scale }\end{array}$ & $\begin{array}{c}\text { Torgerson } \\
\text { Mean }\end{array}$ & $\begin{array}{c}\text { Torgerson } \\
\text { Scale }\end{array}$ \\
\hline $\begin{array}{r}3 \\
4 \\
6 \\
9 \\
12\end{array}$ & $\begin{array}{l}.122 \\
.275 \\
.487 \\
.620\end{array}$ & $\begin{array}{r}-.121 \\
\\
.145 \\
.352 \\
.484\end{array}$ & $\begin{array}{r}-.275 \\
-.144 \\
\\
.175 \\
.278\end{array}$ & $\begin{array}{r}-.487 \\
-.352 \\
-.175 \\
.111\end{array}$ & $\begin{array}{l}-.620 \\
-.484 \\
-.278 \\
-.111\end{array}$ & $\begin{array}{r}-.3758 \\
-.2145 \\
-.0082 \\
.2258 \\
.3732\end{array}$ & $\begin{array}{r}.4210 \\
.6102 \\
.9812 \\
1.6819 \\
2.3616\end{array}$ & $\begin{array}{r}-.3006 \\
-.1716 \\
-.0066 \\
.1806 \\
.2986\end{array}$ & $\begin{array}{r}.5005 \\
.6736 \\
.9849 \\
1.5157 \\
1.9888 \\
\end{array}$ \\
\hline
\end{tabular}

This is the Torgerson scale value for stimulus $\mathrm{k}$, and if $\mathrm{n}=1$, it will be proportional to $S_{\mathrm{k}}$.

Engen's procedure divides the row sums by $\mathrm{I}-1$ instead of $I$, giving

$$
\begin{aligned}
& (I-1)^{-1} \sum_{i} n\left(\log S_{k}-\log S_{i}\right) \\
& \quad=I(I-1)^{-1} n \log S_{k}-(I-1) \sum_{i} \log S_{i}
\end{aligned}
$$

instead of Equation 1. Taking antilogs, the Engen scale value becomes

$$
S_{k}^{n} \mathbf{I}(I-1)^{-1} \exp \left[-(I-1)^{-1} \sum_{i} \log S_{i}\right]
$$

When $\mathrm{n}=1$, Engen's scale value is proportional to $S_{k}^{I(I-1)^{-1}}$. In the case of the present data, $I(I-1)^{-1}$ $=1.25$ and Engen's estimate of $n$ is 1.2455. Thus, Engen's procedure will always indicate a nonlinear power function when the subjective lengths are proportional to the physical lengths. Furthermore, in the event that the exponent of the power function equaled approximately $(I-1) I^{-1}$, the Engen procedure would indicate proportionality when, in fact, the power function $R=\mathrm{cS}^{(I-1) I^{-1}}$ applied.

Experimental evidence strongly supports the conclusion that subjective length is proportional to physical length (Anderson, 1974; Comrey, 1950; Stevens \& Guirao, 1963; Teghtsoonian, 1965; Weiss \& Anderson, 1969) with little evidence to the contrary (e.g., Krueger, 1970). The present reanalysis of Engen's data provides further support. Krantz (1972) was sufficiently convinced of the linearity of subjective length to physical length that he chose length as his basic dimension in his theory of magnitude estimation and cross-modality matching.

Proportionality of subjective length to physical length requires the existence of a ratio scale of subjective length. If ratio judgments are assumed merely to order the line ratio pairs, any power function of the resulting scale will reproduce that ordering. Establishment of a ratio scale would then also require (a) an ordering of the differences of the line pairs, (b) numerical representations of both orderings, and (c) equality of some linear function of the differences representation to some power function of the ratios representation (Krantz, Luce, Suppes, \& Tversky, 1971, section 4.4.3; Parker, Schneider, \& Kanow, 1975). But if we assume that the ratio judgments merely order the line pairs and that a power function of the Torgerson scale values in Table 3 would be a permissible transformation then we must conclude that the almost perfect agreement between the judged ratios in Table 1 and the physical ratios in Table 2 is mere coincidence, reflecting nothing fundamental about the judgment process. For example, a square transformation applied to the scale values for lengths 3 and $4, .5005$ and .6736 , would give scale values of .2505 and .4537 , and a judged ratio of .552 , instead of the predicted value of $.5005 / .6736=.743$, which is very close to the observed value of .756 and the physical ratio of .750 .

I believe that the agreement of the judged ratios with the physical ratios is not fortuitous. I believe it provides information about the judgment process and the psychophysical law. If we require that the scale values reproduce the observed ratios rather than just their rank order, then a similarity transformation is the only permissible transformation, and the exponent of the power law is 1.0 .

The results of Parker, Schneider, and Kanow indicated that if their subjects who judged line length differences used the same subjective scale as did their other subjects who judged line length ratios, then the exponent of the power law is about .5. Setting aside the methodological question concerning using different groups of subjects to obtain the different kinds of judgments, their results indicate that either the exponent is about .5 or subjects do not use the same subjective scale in making difference judgments and ratio judgments of length. The latter alternative is endorsed in general by Marks (1974) who argues for two types of scales, one for magnitudes and the other for dissimilarities, although he hedges when it comes to subjective length (p. 369). Parker et al., preferred to conclude that the exponent in the psychophysical law for length is .5, and that the veridicality of length judgments could be accounted for by assuming that the numbers assigned are a power function of sensory 
magnitude with an exponent around 2.0. According to this argument, the veridicality of length judgment is an accidental reciprocity of two exponents. (The emphasis on accidental is required because if the reciprocity were the result of some adjustment used to obtain veridicality, then there would have to exist a second perceptual judgment system capable of veridicality which would serve as the basis of that adjustment. But if such a second veridical system existed, why would we ever use the first, nonveridical system.) I am afraid that accidental veridicality stretches credulity too far.

\section{REFERENCES}

Anderson, N. H. Cross-task validation of functional measurement using judgments of total magnitude. Journal of Experimental Psychology, 1974, 102, 226-233.

Comrey, A. L. A proposed method for absolute ratio scaling. Psychometrika, 1950, 15, 317-325.

Engen, T. Psychophysics II. Scaling methods. In J. W. Kling \& L. A. Riggs (Eds.), Woodworth \& Schlosberg's experimental psychology (3rd ed.). New York: Holt, Rinehart, \& Winston, 1971.
Krantz, D. H. A theory of magnitude estimation and crossmodality matching. Journal of Mathematical Psychology, 1972, 9, 168-199.

Krantz, D. H., Luce, R. D., Suppes, P., \& Tversky, A. Foundations of measurement (Vol. 1): Additive and polynomial representations. New York: Academic Press, 1971.

Kreuger, L. E. Apparent combined length of two-line and fourline sets. Perception \& Psychophysics, 1970, 8, 210-214.

Marks, L. E. On scales of sensation: Prolegomena to any future psychophysics that will be able to come forth as science. Perception \& Psychophysics, 1974, 16, 358-376.

Parker, S., Schneider, B., \& Kanow, G. Ratio scale measurement of the perceived lengths of lines. Journal of Experimental Psychology: Human Perception and Performance, 1975, 104, 195-204.

Stevens, S. S., \& Guirao, M. Subjective scaling of length and area and the matching of length to loudness and brightness. Journal of Experimental Psychology, 1963, 66, 177-186.

Teghtsoonian, M. The judgment of size. American Journal of Psychology, 1965, 78, 392-402.

Torgenson, W. Theory and methods of scaling. New York: Wiley, 1958.

WE ISS, D. J., \& ANDERSON, N. H. Subjective averaging of length with serial presentation. Journal of Experimental Psychology, $1969,82,52-63$

(Received for publication April 24, 1979; accepted June 26, 1979.) 